\title{
Energy-saving measures in buildings considered as monuments of history and architecture
}

\author{
Alexey Kochev ${ }^{1}$, Mikhail Sokolov ${ }^{1}$, Elena Kocheva ${ }^{1}$, Anna Malysheva ${ }^{2 *}$ and Anna \\ Moskaeva ${ }^{1}$ \\ ${ }^{1}$ Nizhniy Novgorod State University of Architecture and Civil Engineering, 65 Ilyinskaya St., \\ Nizhniy Novgorod, Russia, 603950 \\ ${ }^{2}$ Moscow State University of Civil Engineering, Yaroslavskoye shosse, 26, Moscow, Russia, 129337
}

\begin{abstract}
The number of measures is shown in article, that allow to downsize the consumption of thermal energy in the construction, rehabilitation, reconstruction and maintenance of buildings, which are which are recognized today as monuments of history and architecture.
\end{abstract}

Key words: Unique buildings, Historical and architectural monuments, Energy-saving, Microclimate, Thermal stability

\section{Introduction}

The engineering systems that existed in the ancient unique buildings built in the XVII-XX centuries almost completely destroyed in connection with the purposeful destruction or lack of qualified operation. Along with the tasks of maintaining the required parameters of the microclimate, should be considered and thermophysical aspects used in the rehabilitation, reconstruction, new construction and the transfer of ancient unique buildings that are monuments of the historical and architectural heritage, to year-round operation $[1,2]$.

\section{Materials and methods}

Creation and maintenance of the specified microclimate parameters in historical buildings is possible only if the seasonal heat balances and the characteristics of the heat supply, heating and ventilation systems in the presence of the required heat resistance of enclosing structures and their elements for rational energy use and energy-saving [2].

As a result of the influence of unregulated external natural factors (annual fluctuations in temperature and humidity, the impact of precipitation, soil moisture, groundwater) aging of

\footnotetext{
*Corresponding author: lushinki@mgsu.ru
} 
the materials takes place, leading to a change in the aesthetic, strength characteristics and temperature stresses of the supporting structures (Fig. 1) [3, 4].

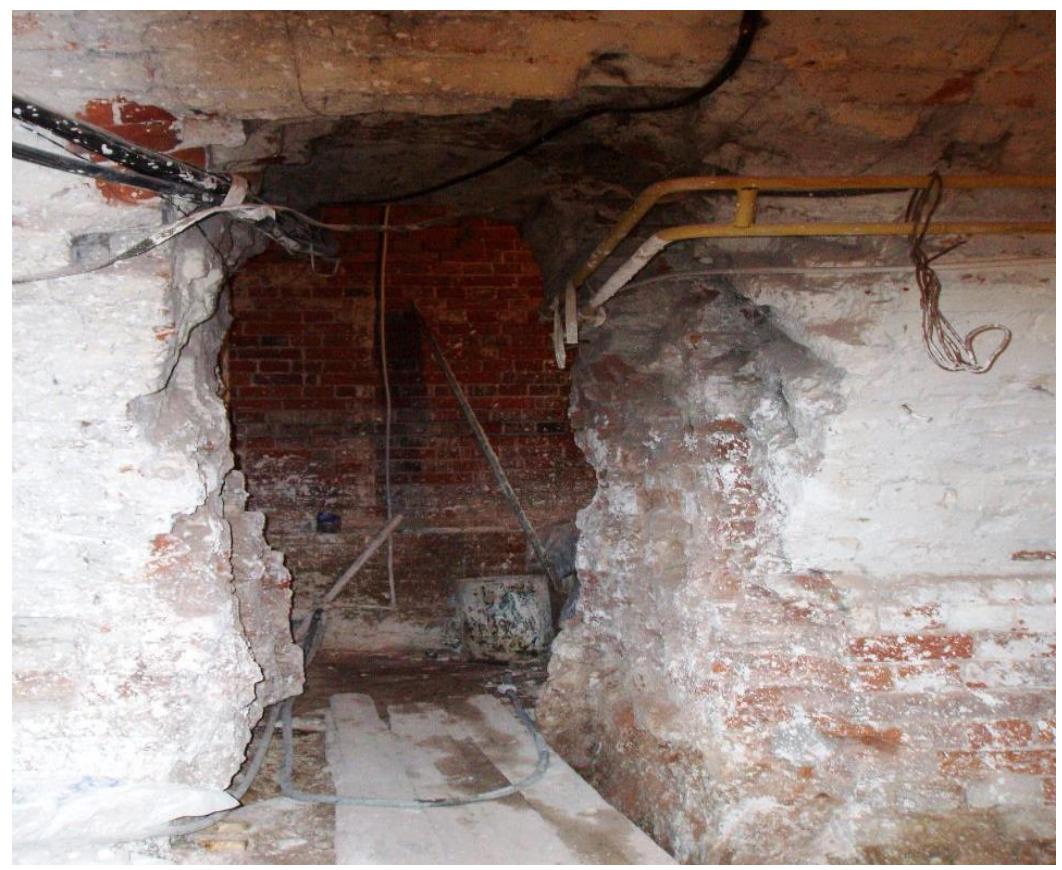

Fig. 1. Type of load-bearing structures of the Cathedral of St. Alexander Nevsky, exposed to moisture, before reconstruction.

Many unique buildings constructed in the central part of Russia in the XVII - XX centuries, according to the thermal characteristics of the exterior walls, are analogues of buildings, which, regulatory requirements should be built with 2003 .

This makes it possible to create and maintain the required microclimate parameters in existing, reconstructed and newly constructed buildings, which are historical and architectural monuments, with minimal costs (Fig. 2) [4].

For the protection of buildings and monuments of ancient architecture from the effects of moisture, as well as for more rapid drying walling, exposed to intensive exposure to moisture and water vapor, used electroosmotic device $[5,6]$.

As a result of electroosmotic dehumidification, the moisture from the layer is filtered to the surface of enclosing structures and evaporated into the volume of the premises, from which it is removed by ventilation systems at the expense of the organized regulated air exchange $[3,8]$.

\section{Researches}

In the process of research, was obtained the economic effect of reducing the drying time of thick-walled structures from 1 to $2.5 \mathrm{~m}$ thick using the method of electroosmosis, compared to natural drying for 5-8 years to the equilibrium air humidity value.

An important role in the formation of heat and air regimes in unique buildings is provided by window openings. The solution of such problems is based on the study of the temperature regime of the outer walls near the window openings and the temperature regime 
of the glazing of the window opening, taking into account the calculated parameters of the outside air, as well as taking into account the location of the window openings. We have developed an engineering method for calculating the thermal conditions of the outer walls near the window opening, depending on the position of the window cover relative to the longitudinal axis of the wall and the thickness of the air space between cover of the window block [7] (Fig. 3).

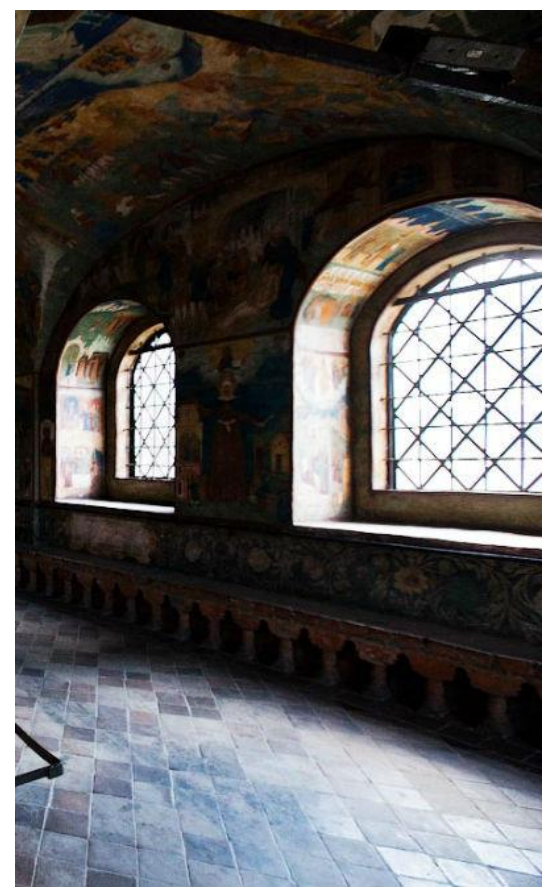

Fig. 2. The walls in the ancient unique buildings have a thickness of more than $1 \mathrm{~m}$.
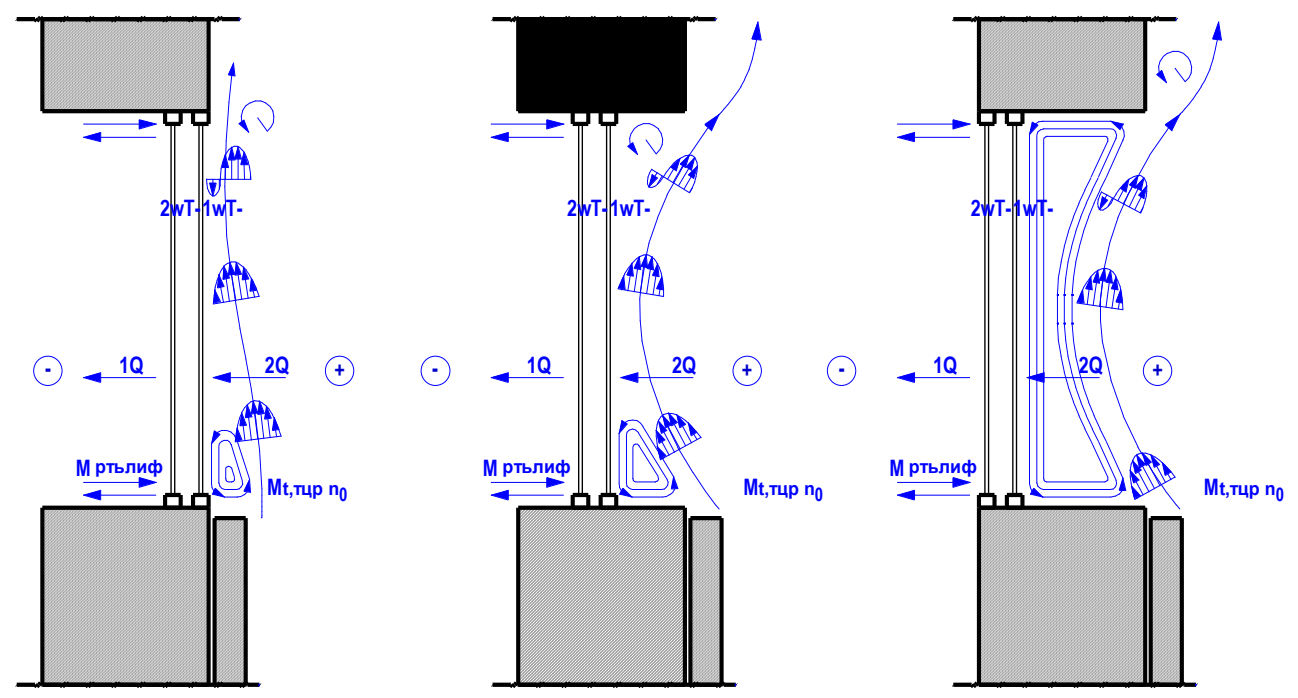

Fig.3. Diagram of convective airflow in glazing, depending on the location of the window sash. 
With the glazing of the outer fences of ancient buildings, which are monuments of history and architecture, a reduction of heat loss is achieved within the range of $10 \div 30 \%$ in the process of optimizing the location of window sashes relative to the longitudinal axis of the wall of the order of $3.5 \div 7 \%$, counting from the total heat loss of the building of the temple, and about $25 \div 30 \%$, of the heat loss in the conventional arrangement structure of window bindings to $1 / 4$ of the wall thickness of the outer surface.

Before designing engineering systems in historic buildings, should ensure the integrity of a building with thermotechnical point of view.

\section{Results}

We obtained theoretical and experimental results on automatic and manual regulation of natural ventilation, depending on the season of the year, the number of people and the power of the heating system in unique buildings. Gravitational pressure is a self-regulating value in unique buildings with a dominant vertical layout $[8,9,10]$.

For each unique building we studied, which is a historical and architectural monument, developed individual card regulation of air exchange on the season of year. Conducting energy-saving measures to regulate the air exchange of gravitational ventilation (aeration) during working hours and non-working hours, can significantly reduce heatconsumption by unique buildings [8].

The use of mechanical ventilation systems in buildings of historical and artistic value, spoils the interior, and leads to a significant increase in operating costs.

\section{Conclusions}

The unique ancient buildings, unlike modern civil buildings, have a number of design features that affect the heat and mass transfer processes in their premises.

In the design of natural ventilation systems in the unique historic buildings should take into account the particular climatic characteristics of the region.

Calculation of natural ventilation systems is recommended for three accounting periods of the year: warm, transitional and cold, taking into account the different occupancy rates of the ancient unique building by people and the characteristics of the heating system $[9,10$, $11,12]$.

We have developed measures to ensure the required controlled gravity air exchange and the normalized air permeability of window bindings with seasonal regulation. This saves up to $30 \%$ of the heat compared to the absence of automatic regulation and more than $50 \%$ compared to the use of mechanical ventilation.

\section{References}

1. N.F. Filatov, Dome, looking to the sky: Nizhny Novgorod temple architecture of the XVII-XX (1996)

2. A.G. Kochev, Climate of the Orthodox churches: monograph (2004).

3. A.G. Kochev, O.V. Fedorova, M.M. Sokolov, Proceedings of universities, 2-3, 60-67 (2013)

4. V.N. Kupriyanov, Designing heat insulation of enclosing structures (2011)

5. B.V. Matveyev, Drying walls by electroosmosis (1963) 
6. O.M. Fridman, Electroosmotic method for eliminating the dampness of the walls of buildings (1971)

7. A.G. Kochev, A.S. Sergienko, Russian scientific journal, 3 (46), 285-289 (2015)

8. AG Kochev, A.S. Sergienko, Russian scientific journal, 1 (44), 282-286 (2015)

9. M.M. Sokolov, E.A. Kocheva, M.A. Kocheva, A.S. Moskaeva, E.V. Smirnova, Scientific Review. Engineering sciences, 6., 36-38 (2016)

10. M.M. Sokolov, E.A. Kocheva, M.A. Kocheva, A.S. Moskaeva, E.V. Smirnova, Scientific Review. Engineering sciences, 6, 39-42 (2016)

11. Parfentieva N., Samarin O., Lushin K., Paulauskaite S., ICEE 2008 Conference Proceedings, 7, 854-858 (2008).

12. Gagarin V.G., Lushin K.I., Kozlov V.V., Neklyudov A.Yu, Procedia Engineering, 146, 103-111 (2016) 